\title{
Técnica de separação da membrana de Descemet para transplante de células endoteliais da córnea: estudo experimental em coelhos
}

\author{
Technique for separating Descemet membrane for corneal endothelial cells \\ transplantation: experimental study in rabbits
}

\author{
Daniel Wasilewski ${ }^{1}$ \\ Alexandre Lass Siqueira ${ }^{2}$ \\ Lawrence Rife ${ }^{3}$ \\ Eduardo Arana ${ }^{4}$ \\ Hamilton Moreira ${ }^{5}$ \\ Ronald Smith ${ }^{6}$
}

Trabalho realizado no Departamento de Oftalmologia do Doheny Eye Institute, Keck School of Medicine, University of Southern California - Los Angeles (CA) - EUA e no Instituto de Pesquisas Médicas da Faculdade Evangélica do Paraná - Curitiba (PR) - Brasil.

Trabalho apresentado ao Programa de pós-graduação em Princípios da Cirurgia da Faculdade Evangélica do Paraná para obtenção do grau de Mestre.

${ }^{1}$ Mestre em Clínica Cirúrgica pela Faculdade Evangélica do Paraná - Curitiba (PR) - Brasil. Ex-Fellow do Doheny Eye Institute. University of Southern Califórnia - Los Angeles (CA) - EUA.

${ }^{2}$ Ex-Fellow do Doheny Eye Institute. University of Southern Califórnia - Los Angeles (CA) - EUA

Chefe do Laboratório de Pesquisa Básica do Doheny Eye Institute, University of Southern California - Los Angeles (CA) - EUA.

${ }^{4}$ Médico residente de oftalmologia pelo Hospital de Olhos do Paraná - Curitiba (PR) - Brasil.

${ }^{5}$ Doutor em Oftalmologia pela Universidade Federal de São Paulo - UNIFESP - São Paulo (SP) - Brasil

${ }^{6}$ Presidente do Doheny Eye Institute, Universidade do Sul da Califórnia - Los Angeles (CA) - EUA.

Endereço para correspondência: Daniel Wasilewski. Rua Coronel Dulcídio, 199 - 5ำ andar - Curitiba (PR) CEP 80420-170

E-mail: dwoftalmo@yahoo.com.br

Recebido para publicação em 02.12 .2008

Última versão recebida em 20.01.2010

Aprovação em 21.01.2010

\begin{tabular}{|l|}
\hline RESUMO \\
\hline Objetivo: Avaliar a porcentagem de dano endotelial induzido por uma \\
técnica cirúrgica para a separação da membrana de Descemet contendo \\
endotélio sadio, analisar a viabilidade e eficácia desta técnica, e avaliar \\
a porcentagem de dano endotelial causado pela inversão da córnea em \\
câmara anterior artificial. Métodos: As córneas de três grupos de 12 \\
coelhos da linhagem Nova Zelândia foram avaliadas. O grupo 1 foi \\
usado como controle; portanto, as córneas foram analisadas após \\
coletadas e trepanadas. O grupo 2 foi analisado após a inversão da \\
córnea (endotélio para cima na posição convexa), montada em câmara \\
anterior artificial, para o cálculo da porcentagem do dano endotelial \\
induzido por esta inversão. O grupo 3 foi avaliado após a separação \\
entre a membrana de Descemet e o estroma com o uso de substância \\
viscoelástica em córneas invertidas e montadas em câmara anterior \\
artificial. O dano endotelial foi avaliado por meio de fotografias digitais \\
tiradas no microscópio após impregnar o endotélio com vermelho de \\
alizarina. Amostras do grupo 3 foram processadas para avaliação \\
histopatológica. Resultados: O grupo 3 (separação viscoelástica) apre- \\
sentou um índice de lesão celular endotelial de $10,06 \%$ o grupo 2 \\
apresentou um índice de 3,58\% e o grupo controle um índice de $0,18 \%$ \\
de lesão celular endotelial (p<0,05). A avaliação histológica das cór- \\
neas do grupo 3 revelou que aproximadamente 120 $\mu$ m de espessura \\
estromal manteve-se aderido à membrana de Descemet. Conclusão: \\
Esta técnica deve ser melhor investigada, pois é uma alternativa viável \\
e eficaz de separação da membrana de Descemet para transplante \\
celular endotelial, já que o porcentual de dano celular induzido é de \\
10,06\%. A porcentagem de dano celular causado pela inversão da \\
córnea em câmara anterior artificial foi de 3,58\%. \\
\hline
\end{tabular}

Descritores: Córnea/cirurgia; Transplante de córnea; Membrana de Descemet; Epitélio posterior; Coelhos

\section{INTRODUÇÃOO}

Nos últimos 80 anos, a conduta tradicional à substituição do endotélio corneano doente tem sido o uso da ceratoplastia penetrante em toda a sua espessura. Avanços recentes em novas técnicas têm iniciado o interesse na ceratoplastia lamelar posterior como uma terapia cirúrgica mais específica e eficaz para a substituição do endotélio ${ }^{(1)}$. 
A maioria das ceratoplastias é realizada devido à disfunção das células endoteliais ${ }^{(2)}$, como na distrofia endotelial de Fuchs e na ceratopatia bolhosa pseudofácica e afácica ${ }^{(3)}$. Nestes casos, a cirurgia ideal consiste em manter a integridade da córnea receptora e substituir somente a membrana de Descemet (MD) com o endotélio lesado. Isso minimiza o astigmatismo pós-operatório, o longo tempo de cicatrização da porção estromal e as complicações relacionadas às suturas ${ }^{(4)}$.

Técnicas atuais para a substituição das camadas posteriores lesadas da córnea incluem a ceratoplastia lamelar endotelial profunda (DLEK) ${ }^{(5-6)}$, a ceratoplastia endotelial com descolamento da Descemet (DSEK) $)^{(7)} \mathrm{e}$, mais recentemente, a ceratoplastia endotelial da membrana de Descemet $(\mathrm{DMEK})^{(8)}$. Estas técnicas envolvem a dissecção da MD e endotélio do olho doador com a finalidade de obter o disco posterior para transplante e criar um acesso no olho receptor para remover e substituir o disco posterior lesado ${ }^{(4)}$. Estas técnicas demonstram, quando realizadas com sucesso, melhores resultados que a técnica de ceratoplastia penetrante e o risco de rejeição é mínimo ${ }^{(1,6-11)}$. No entanto, a principal desvantagem destas técnicas é a dificuldade na realização do procedimento, especialmente na separação entre a MD e o estroma da córnea doadora.

É muito importante que um número suficiente de células endoteliais sadias do disco doador sobrevivam à preparação e ao transplante ${ }^{(4)}$. Por isso, deve-se preservar a integridade do endotélio durante todo o procedimento.

Este estudo tem como objetivo avaliar a porcentagem de dano endotelial induzido por uma técnica cirúrgica para a separação da MD contendo células endoteliais sadias, analisar a viabilidade e eficácia desta técnica, e avaliar a porcentagem de dano endotelial induzido pela inversão da córnea em câmara anterior artificial.

\section{MÉTODOS}

\section{Delineamento experimental}

Este estudo experimental, prospectivo e controlado, foi realizado sob coordenação do "Doheny Vision Research Center" (DVRC). O uso dos animais neste estudo ocorreu conforme a resolução da ARVO ("Association for Research in Vision and Ophthalmology") no uso de animais em pesquisa. Todos os animais foram abrigados em instalações aprovadas pela Associação Americana de Ciência em Animais de Laboratório. O projeto de pesquisa deste estudo foi aprovado pela comissão de ética em pesquisa da "University of Southern Califórnia" (USC) e do "Doheny Eye Institute".

\section{População e local do estudo}

Foram analisadas 19 córneas de 12 coelhos albinos, machos, da linhagem Nova Zelândia (Irish Farms, Norco, CA), sadios e pesando entre 2,3 e 2,7 kg. Cinco córneas foram descartadas do estudo devido a lesões pré-existentes nestes tecidos.
O presente estudo experimental foi desenvolvido nas dependências do "Doheny Vision Research Center", na "University of Southern California".

\section{Grupos em estudo}

As córneas foram divididas e separadas aleatoriamente em três grupos. O grupo 1 foi o grupo controle, composto por seis córneas. O grupo 2 foi composto por sete córneas e analisado após a montagem das córneas em câmara anterior artificial na posição inversa, com o endotélio virado para cima. Foi calculado o dano às células endoteliais causado por esta inversão. O grupo 3, composto por seis córneas, foi avaliado após a inversão das córneas em câmara anterior artificial (endotélio virado para cima) e separação entre a MD e o estroma corneano, utilizando substância viscoelástica.

\section{Procedimento anestésico e eutanásia}

Os 12 coelhos foram anestesiados com ketamina (40 mg/ $\mathrm{kg}$ ) e xylazina $(8 \mathrm{mg} / \mathrm{kg})$. Imediatamente após a anestesia, foi realizada a eutanásia dos animais por meio de overdose de pentobarbital sódico ( $\geq 333 \mathrm{mg} / \mathrm{kg}$ ) via intracardíaca ou intravenosa.

\section{Procedimento cirúrgico}

Todas as cirurgias foram realizadas no mesmo local, pelo mesmo cirurgião, utilizando-se microscópio cirúrgico e seguindo-se a mesma técnica cirúrgica em todos os animais.

Após a eutanásia, peritomia conjuntival $360^{\circ}$ foi realizada e o segmento anterior de cada olho, contendo córnea, cristalino, íris e corpo ciliar, foi removido com um anel escleral de 3 a $4 \mathrm{~mm}$. O segmento anterior foi transferido com o epitélio corneano virado para baixo e fixado em um bloco de trepanação do tipo Barron. Isto permitiu a remoção do cristalino, íris e corpo ciliar com o cuidado de não dobrar ou torcer a córnea, o que poderia danificar o endotélio. Durante a remoção do cristalino, íris e corpo ciliar, solução salina balanceada (BSS) heparinizada $(40 \mu / \mathrm{ml})$ foi aplicada sobre a córnea a fim de prevenir a formação de fibrina.

Após a remoção das estruturas internas do segmento anterior, foi usado um trépano de Barron $(7,5 \mathrm{~mm})$ para delicadamente marcar a superfície do endotélio como referência nos passos seguintes. Para as córneas do grupo 1 (controle), foi realizada a trepanação completa de toda a espessura corneana, a qual foi então processada para impregnação e fotografias do endotélio.

As córneas dos grupos 2 e 3 foram transferidas para uma câmara anterior artificial e orientadas com o endotélio virado para cima (posição convexa). No grupo 2, as córneas invertidas e fixadas na câmara anterior artificial foram mantidas nesta posição por um período de 10 minutos, com a finalidade de simular o tempo que levaria para a separação viscoelástica que ocorreu no grupo 3. Após esse período, as córneas eram então transferidas para um bloco de trepanação (epitélio para baixo), trepanadas no mesmo diâmetro do 
grupo $1(7,5 \mathrm{~mm})$ e preparadas para impregnação e fotografias do endotélio.

No grupo 3, utilizando um microscópio cirúrgico (Zeiss OPMI-6), uma lâmina de bisturi foi usada para criar uma penetração rasa, de aproximadamente 100 micra, através da MD em uma das áreas marcadas pelo trépano. Uma cânula de calibre 27 gauge foi inserida por essa incisão e posicionada entre a MD e o estroma corneano adjacente. Substância viscoelástica foi injetada através dessa cânula com a finalidade de criar uma separação hidrostática entre as duas estruturas. A cânula foi usada para fazer uma varredura sob a MD enquanto o viscoelástico era injetado até que toda a extensão da membrana marcada pelo trépano $(7,5 \mathrm{~mm})$ parecesse estar separada do estroma. Uma lâmina de bisturi curva (crescente) foi utilizada para finalizar a dissecção do estroma nas poucas áreas que ainda estavam aderidas à MD. Uma espátula larga de $8 \mathrm{~mm}$ foi usada para deslizar sob a membrana solta e separá-la da maior parte do estroma, transferindo a MD contendo endotélio e uma fina camada de estroma para uma lâmina de vidro, onde o endotélio da membrana foi então preparado para impregnação e fotografias.

\section{Impregnação do endotélio}

Vermelho de alizarina, dissolvido em solução isotônica $(0,2 \mathrm{~g} / 100 \mathrm{~mL})$, foi colocado na superfície endotelial da membrana. O corante foi deixado por 2 minutos, enxaguado com solução isotônica e, posteriormente, aplicado por mais 1 minuto, com a finalidade de melhor evidenciar a impregnação das junções celulares. Após o último enxágue, a membrana foi coberta com uma lamínula de vidro, utilizando viscoelástico para prevenir o toque da lamínula no endotélio e consequente indução de lesão celular.

\section{Fotografia}

Uma câmera digital (Nikon 990 CoolPix) foi usada para fotografar o endotélio por meio de um microscópio laboratorial com um aumento de 10X. Uma série de fotografias não sobrepostas foi tirada de cada superfície endotelial das membranas para documentar o máximo de área possível, sendo que aproximadamente $90 \%$ da área total de cada tecido foi fotografado.

\section{Avaliação histológica}

Após o procedimento, as membranas do grupo três foram fixadas em solução de formaldeído a $4 \%$ embebido em parafina, seccionadas e fixadas com H\&E para avaliação histológica.

\section{Análise morfométrica e estatística do dano endotelial}

As áreas danificadas foram identificadas devido à coloração avermelhada mais intensa de células únicas ou grupos de células onde elas foram traumatizadas. Estas áreas foram digitalmente intensificadas utilizando Adobe Photoshop e quantificadas utilizando o programa Scion image beta 4.02 (scioncorp.com). A porcentagem de dano endotelial foi calculada dividindo a área danificada pela área total do endotélio fotografado.
Recorreu-se à análise descritiva dos dados por meio de quadros e gráficos. Para a comprovação do objetivo levantado nesse trabalho, foram utilizados os testes não-paramétricos Kruskal-Wallis e Mann-Whitney. O nível de significância adotado foi menor que $5 \%(\mathrm{p}<0,05)$.

\section{RESULTADOS}

A porcentagem de dano endotelial induzido pelo procedimento no grupo 1 (controle) foi de $0,18 \%$ (Figura 1).

No grupo 2 (córnea invertida), a perda celular endotelial foi de 3,58\% (Figura 2) e no grupo 3, após separação viscoelástica entre a MD e o estroma, a porcentagem de lesão endotelial foi de $10,06 \%$ (Figura 3 ).

O quadro 1 mostra o porcentual de lesão encontrado nos grupos estudados.

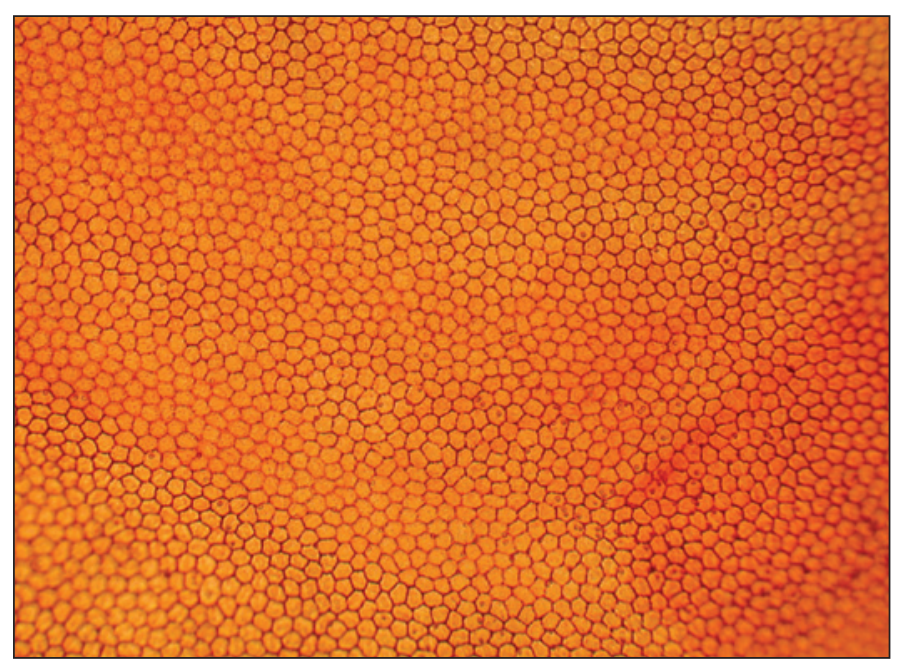

Figura 1 - Fotografia do endotélio no grupo 1 (controle)

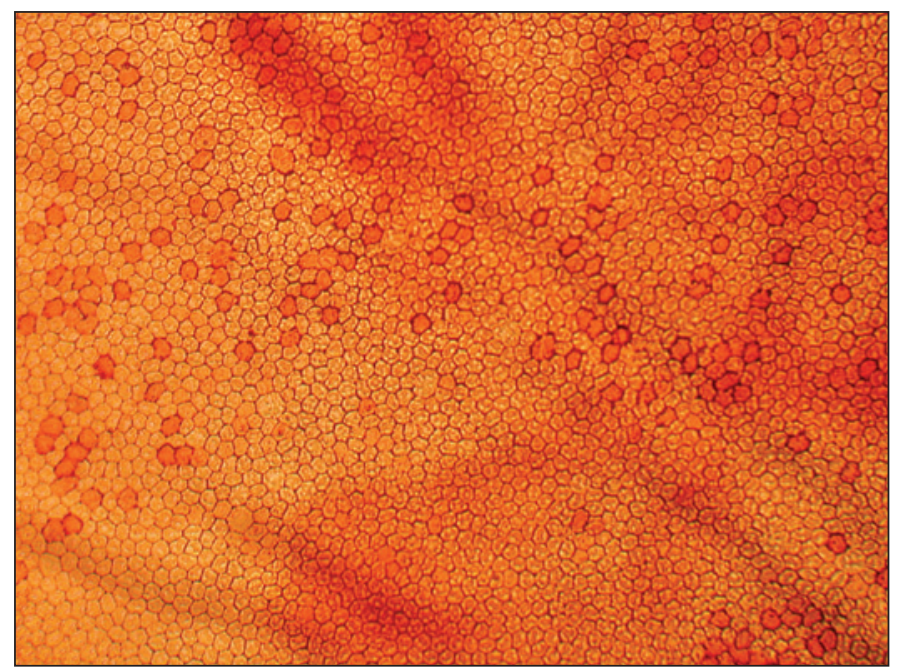

Figura 2 - Fotografia do endotélio no grupo 2: áreas mais escuras correspondem às células lesadas 


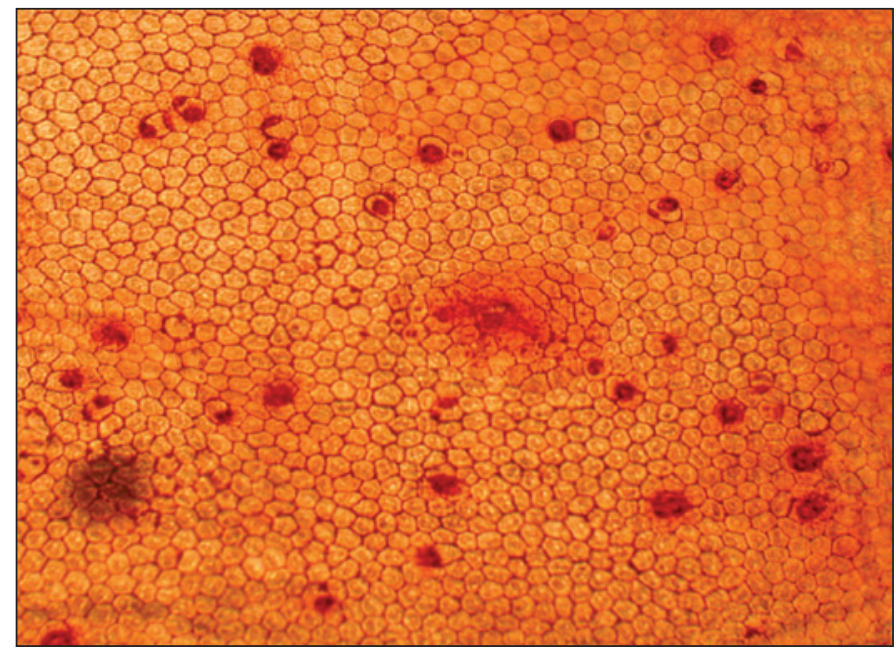

Figura 3 - Fotografia do endotélio no grupo 3

\begin{tabular}{|c|c|c|c|c|c|c|}
\hline \multicolumn{7}{|c|}{ Quadro 1. Porcentual de lesão nos grupos estudados } \\
\hline Grupos & $\mathbf{N}^{\circ}$ & Média & $\begin{array}{l}\text { Desvio } \\
\text { padrão }\end{array}$ & Mínimo & Máximo & Mediana \\
\hline Controle & 6 & 1,42 & 2,05 & 0,00 & 4,25 & 0,18 \\
\hline Grupo 2 & 7 & 7,06 & 6,42 & 2,43 & 20,00 & 3,58 \\
\hline Grupo 3 & 6 & 11,90 & 8,97 & 2,98 & 28,45 & 10,06 \\
\hline
\end{tabular}

O estudo histológico das membranas separadas do grupo 3 demonstrou que aproximadamente $120 \mu \mathrm{m}$ de espessura estromal permanecia aderida à MD (Figura 4).

Na comparação entre os três grupos, em relação ao porcentual de lesão, foi observado que o grupo 3 apresentou maior índice de lesão (medianas de $0,18 \% ; 3,58 \%$ e 10,06\%) $(\mathrm{p}=0,020)$ (Gráfico 1).

Foi observada diferença significativa entre o grupo 1 (controle) e o grupo 3, sendo encontrado maior índice de lesão no grupo 3 (medianas de $0,18 \%$ e $10,06 \%)(p=0,010)$.

$\mathrm{Na}$ comparação entre os grupos 2 e 3, não foi observada diferença significativa. No entanto, ressalta-se que, entre o grupo 1 (controle) e o grupo 2, foi observado maior índice de lesão para o grupo 2 , mas sem diferença significativa $(\mathrm{p}=0,063)$ (probabilidade limítrofe que indica tendência).

\section{DISCUSSÃO}

O ideal para qualquer procedimento que substitui o endotélio seria apresentar uma córnea opticamente perfeita, superfície topográfica regular e sem mudanças significantes no astigmatismo, poder dióptrico corneano altamente previsível e um endotélio sadio após o procedimento. As técnicas atuais de transplante endotelial têm demonstrado todas estas vantagens de forma bastante satisfatória. Além disso, não apresentam complicações relacionadas à sutura, como ceratite infec-

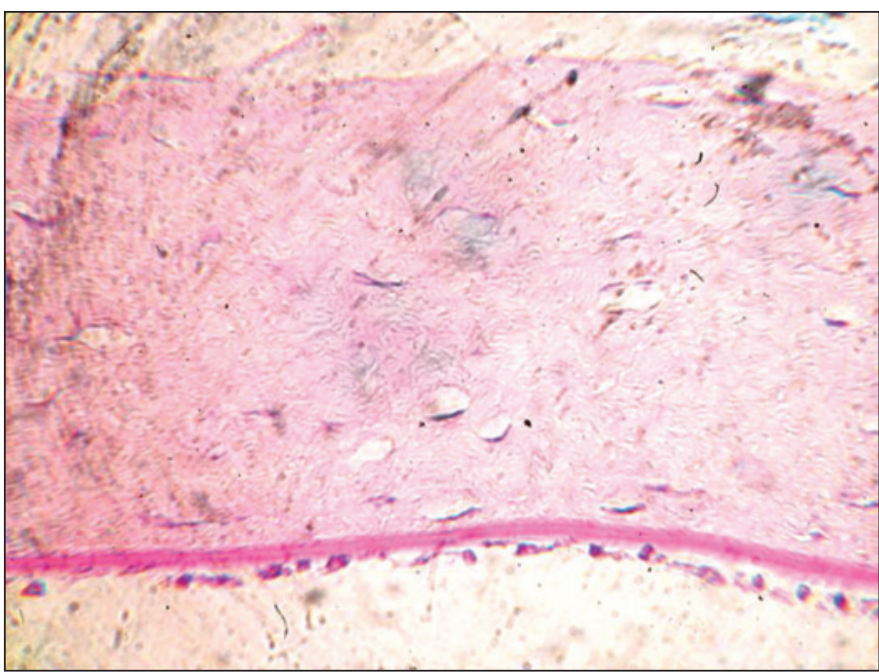

Figura 4 - Fotografia histológica do endotélio + MD + estroma posterior da córnea

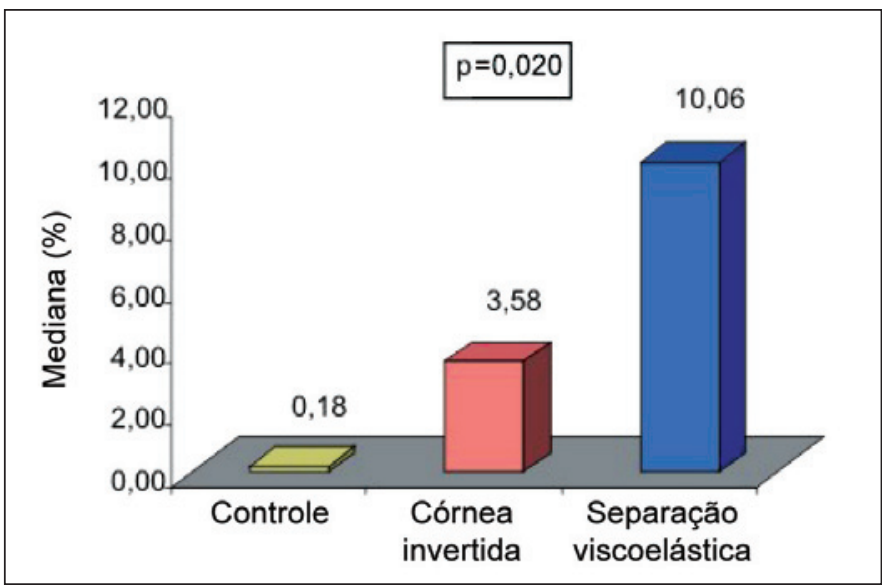

Gráfico 1 - Porcentual de lesão nos grupos estudados

ciosa, úlcera corneana, "melting", vascularização da córnea doadora e rejeição epitelial e estromal. As complicações relacionadas à cicatrização podem ser minimizadas, já que o epitélio e o estroma não são substituídos ${ }^{(5)}$. Na ceratoplastia penetrante, o astigmatismo irregular é a principal complicação, e a instabilidade refracional se mantém anos após a cirurgia ${ }^{(4)}$.

Outra grande vantagem das técnicas de ceratoplastia endotelial é que mesmo córneas apresentando opacidades anteriores podem ser utilizadas para transplante, o que é impossível acontecer em um transplante penetrante, o qual requer boa qualidade do tecido doador em toda a sua espessura ${ }^{(5)}$.

Por obter melhores resultados clínicos, muitos pacientes podem querer optar por qualquer tipo de transplante endotelial ao invés da ceratoplastia penetrante. No entanto, para os cirurgiões, a maior dificuldade parece ser a preparação do tecido doador. Na maioria dos países, bancos de olhos dispõem aos cirurgiões botões corneoesclerais, sendo que o disco lamelar posterior deve ser dissecado manualmente ou 
com o auxílio de um microcerátomo, imediatamente antes ou durante a cirurgia ${ }^{(12)}$.

Após a publicação da técnica da excisão da MD da córnea receptora (descemetorrexis), foi demonstrado ser possível a retirada somente da camada endotelial lesada da córnea, mantendo a integridade de todo o estroma posterior e deixando uma superfície lisa e ideal para receber o tecido doador ${ }^{(13)}$. Após a implantação desta nova técnica na prática cirúrgica, tornou-se necessário a busca por novos métodos de retirada do endotélio doador sadio e separado do estroma posterior. Porém, pouco se estuda sobre a preparação do tecido doador. Alguns autores em 2002 foram os primeiros a descrever uma técnica de preparação da MD com endotélio doador utilizando câmara anterior artificial e dissecando o endotélio da córnea na posição convexa (virado para cima), assim como foi feito no presente estudo ${ }^{(14)}$. Outros autores demonstraram que, neste tipo de preparação, não há necessidade de instrumentos cirúrgicos personalizados ${ }^{(15)}$.

Recentemente, foi publicada uma variação no método de preparação do endotélio doador, em que a MD foi dissecada em câmara anterior artificial com o endotélio para cima, utilizando uma espátula de ciclodiálise. A perda endotelial média foi de $8,46 \pm 6,9 \%$ e a morfologia celular manteve a sua integridade ${ }^{(16)}$.

Neste presente estudo, foi desenvolvida uma técnica similar, sendo que a principal diferença consistiu na utilização de substância viscoelástica, com o objetivo de diminuir a lesão endotelial e maior facilidade de dissecção.

Um estudo retrospectivo não randomizado comparou a dissecção do disco doador utilizando microcerátomo automatizado com a dissecção manual em 330 pacientes submetidos à técnica de DSEK. Os resultados mostraram que não houve diferença entre os grupos em relação à acuidade visual melhor corrigida no terceiro e sexto mês após a cirurgia, porém, a recuperação visual foi mais rápida no grupo em que foi utilizado o microcerátomo ${ }^{(17)}$. Portanto, percebe-se que a principal vantagem no uso do microcerátomo é na recuperação visual mais rápida. Mas deve-se salientar que ainda, em diversos países, inclusive no Brasil, muitos centros não dispõem de um microcerátomo automatizado para realizar esse tipo de procedimento.

Os resultados da técnica deste estudo foram bastante satisfatórios. Após toda a remoção e separação entre a MD e o estroma, obteve-se 10,06 $\pm 8,9 \%$ de lesão endotelial, mantendo a integridade morfológica das células. Neste aspecto, o resultado foi bastante semelhante ao encontrado por outros autores, apesar de eles não terem utilizado substância viscoelástica ${ }^{(16)}$. Também foi tentado diminuir ao máximo a aderência estromal à MD, porém, uma lamela estromal de $120 \mu \mathrm{m}$ ainda se manteve aderida.

Este presente estudo foi o primeiro a avaliar a porcentagem de lesão endotelial induzida somente pelo procedimento de inversão da córnea em câmara anterior artificial. Durante 10 minutos, o endotélio foi mantido na posição convexa (para cima), simulando o tempo de dissecção. A partir disso, obser- vou-se que o dano celular foi de 3,58\%. Maior do que no grupo controle, que foi de $0,18 \%$, porém estatisticamente nãosignificativo.

Dessa forma, é pertinente observar que a inversão da córnea com o endotélio para cima em câmara anterior artificial é vantajosa, já que não induz lesão significativa e facilita muito a dissecção manual da MD.

Esta técnica cirúrgica requer investigação futura a fim de avaliar a porcentagem de dano endotelial em cada estágio do transplante, inclusive no período pós-operatório. Porém, devido ao baixo índice de lesão endotelial induzida por este procedimento, acredita-se que o transplante de endotélio com a utilização desta técnica possa resultar em rápida recuperação visual, melhores resultados pós-operatórios e menores índices de complicações em pacientes que apresentam disfunção endotelial.

\section{CONCLUSÕES}

A técnica de separação da MD contendo células endoteliais para transplante de endotélio descrita neste estudo mostrou que:

1. Este procedimento induz 10,06\% de lesão endotelial.

2. Esta técnica é viável e eficaz.

3. A inversão da córnea em câmara anterior artificial induz $3,58 \%$ de lesão endotelial.

\section{ABSTRACT}

Purpose: To evaluate the percentage of endothelial cell damage induced during a surgical technique of Descemet's membrane separation containing healthy endothelium, analyze the viability and efficacy of this technique, and evaluate the percentage of endothelial cell damage caused by inversion of the cornea on an artificial anterior chamber. Methods: The corneas from three groups of $12 \mathrm{New}$ Zealand rabbits were evaluated. The Group one was used as the control, so the corneas were analyzed after collected and trephinated. The Group two was analyzed after inversion of the cornea (endothelial side up at a convex shape) mounted on an artificial anterior chamber to calculate the percentage of endothelial cell damage caused by this inversion. The Group three was evaluated after the separation between the Descemet's membrane and the stroma using viscoelastic substance in corneas inverted and mounted on an artificial anterior chamber. The endothelial cell damage was analyzed by digital photographs taken under a microscope after staining the endothelium with alizarin red. Group three samples were processed for histologic evaluation. Results: The Group three (viscoelastic separation) showed an index of endothelial cell damage of $10.06 \%$, the Group two showed an index of $3.58 \%$ and the control group an index of $0.18 \%$ of endothelial cell damage $(\mathrm{p}<0.05)$. Histological evaluation of the Group three corneas revealed that 
approximately a $120 \mu \mathrm{m}$ thickness of stroma remained attached to the Descemet's membrane. Conclusion: This technique should be better investigated because it is a viable and efficient alternative of Descemet's membrane separation for endothelial cells transplantation, since the percentage of induced cell damage is $10.06 \%$. The percentage of endothelial cell damage caused by inversion of the cornea on an artificial anterior chamber was $3.58 \%$.

Keywords: Cornea/surgery; Corneal transplantation; Descemet membrane; Endothelium, corneal; Rabbits

\section{REFERÊNCIAS}

1. Terry MA. Endothelial replacement: the limbal pocket approach. Ophthalmol Clin North Am. 2003;16(1):103-12.

2. Behrens A, Ellis K, Li L, Sweet PM, Chuck RS. Endothelial lamellar keratoplasty using an artificial anterior chamber and a microkeratome. Arch Ophthalmol. 2003;121(4):503-8.

3. Yaghouti F, Nouri M, Abad JC, Power WJ, Doane MG, Dohlman CH. Keratoprosthesis: preoperative prognostic categories. Cornea. 2001;20(1):19-23.

4. Zhu Z, Rife L, Yiu S, Trousdale MD, Wasilewski D, Siqueira A, Smith RE Technique for preparation of the corneal endothelium-Descemet membrane complex for transplantation. Cornea. 2006;25(6):705-8

5. Melles GR, Eggink FA, Lander F, Pels E, Rietveld FJ, Beekhuis WH, Binder PS. A surgical technique for posterior lamellar keratoplasty. Cornea. 1998; 17(6):618-26.
6. Terry MA, Ousley PJ. Deep lamellar endothelial keratoplasty in the first United States patients: early clinical results. Cornea. 2001;20(3):239-43.

7. Price FW Jr, Price MO. Descemet's stripping with endothelial keratoplasty in 200 eyes: Early challenges and techniques to enhance donor adherence. J Cataract Refract Surg. 2006;32(3):411-8.

8. Melles GR, Ong TS, Ververs B, van der Wees J. Descemet membrane endothelial keratoplasty (DMEK). Cornea. 2006;25(8):987-90.

9. Melles GR, Lander F, Van Dooren BT, Pels E, Beekhuis WH. Preliminary clinical results of posterior lamellar keratoplasty through a sclerocorneal pocket incision. Opththalmology. 2000;107(10):1850-6; discussion 1857

10. Terry MA, Ousley PJ. Deep lamellar endothelial keratoplasty: visual acuity, astigmatism, and endothelial survival in a large prospective series. Ophthalmology. 2005;112(9):1541-49.

11. Panda A, Bageshwar LM, Ray M, Singh JP, Kumar A. Deep lamellar keratoplasty versus penetrating keratoplasty for corneal lesions. Cornea. 1999;18(2): $172-5$.

12. Melles GR. Posterior lamellar keratoplasty: DLEK to DSEK to DMEK. Cornea. 2006;25(8):879-81.

13. Melles GR, Wijdh RH, Nieuwendaal CP. A technique to excise the Descemet membrane from a recipient cornea (descemetorhexis). Cornea. 2004;23(3):286-8

14. Melles GR, Lander F, Rietveld FJ. Transplantation of Descemet's membrane carrying viable endothelium through a small scleral incision. Cornea. 2002; 21(4):415-8. Comment in: Cornea. 2002;21(8):840; author reply 840.

15. Suwan-Apichon O, Rizen M, Reyes JM, Herretes S, Behrens A, Stark WJ, et al. A new donor cornea harvesting technique for posterior lamellar keratoplasty. Br J Ophthalmol. 2005;89(9):1100-1

16. Ignacio TS, Nguyen TT, Sarayba MA, Sweet PM, Piovanetti O, Chuck RS, et al. A technique to harvest Descemet's membrane with viable endothelial cells for selective transplantation. Am J Ophthalmol. 2005;139(2):325-30.

17. Price MO, Price FW. Descemet's stripping with endothelial keratoplasty: comparative outcomes with microkeratome-dissected and manually dissected donor tissue. Ophthalmology. 2006;113(11):1936-42.

\section{ABO ELETRONNGO}

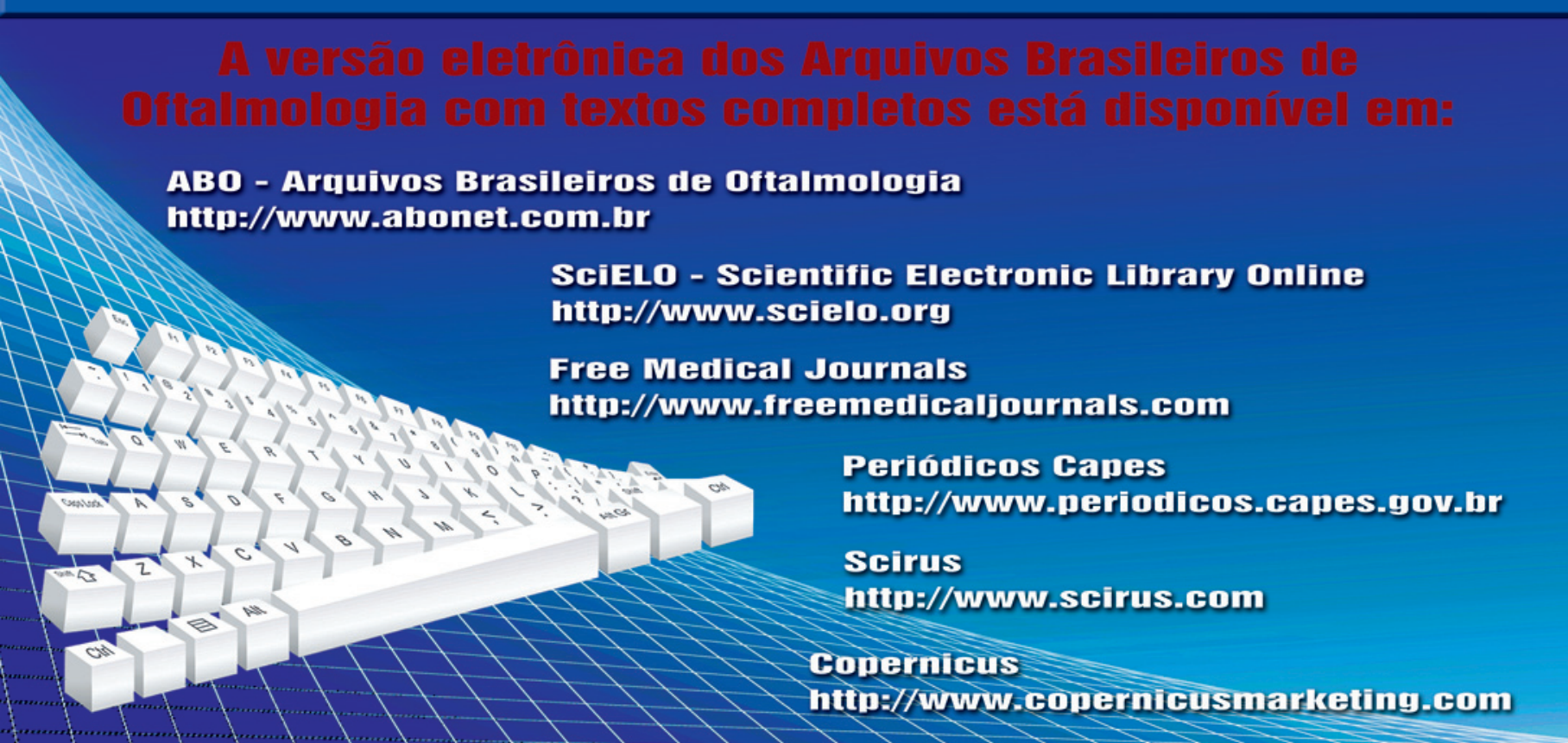

